\title{
ARQUIVO, DOCUMENTO E MEMÓRIA NA CONCEPÇÃO DISCURSIVA
}

ARCHIVE, DOCUMENT AND MEMORY IN THE DISCURSIVE CONCEPTION

Ludmila Ferrarezi - mila_fer2003@yahoo.com.br Discente do Curso de Ciências da Informação e da Documentação da Faculdade de Filosofia, Ciências e Letras de Ribeirão Preto da Universidade de São Paulo (USP) Lucília Maria Sousa Romão - tantpalavras@uol.com.br Professora Dra. do Curso de Ciências da Informação e da Documentação da Faculdade de Filosofia, Ciências e Letras de Ribeirão Preto da Universidade de São Paulo (USP)

\section{Resumo}

Esse artigo intenta, à luz da teoria do discurso, visitar a noção de arquivo, buscando compreender como os sentidos sobre ele constituem um lugar científico já consolidado e como é possível um diálogo com a concepção de discurso. Para tal, interpretamos um corpus colhido na página eletrônica do Movimento dos Trabalhadores Rurais Sem Terra.

Palavras-chave: Arquivo. Documento arquivístico. Memória discursiva. Movimento dos Trabalhadores Rurais Sem Terra. Análise do Discurso.

A certeza de que tudo está escrito nos anula ou nos fantasmagoriza - Jorge Luis Borges (A biblioteca de Babel)

\section{INTRODUÇÃO}

Promovendo um diálogo entre a Análise do Discurso e as áreas de pesquisa nas quais se inserem as discussões sobre o arquivo, a saber, Arquivística, História e Ciência da Informação, buscamos tecer relações de concordância e conflito, apontando como o arquivo, o documento e a memória podem ser compreendidos sob uma outra ótica e mobilizados para analisar diversos documentos, como os arquivos eletrônicos sobre o Movimento dos Trabalhadores Rurais Sem Terra (MST). 
A Análise do discurso (AD) é fundamentada, principalmente, pelos conceitos de sujeito, discurso, memória e ideologia e pode colaborar com diversas áreas, apresentando uma outra maneira de se pensar questões como, por exemplo, as referentes aos arquivos.

O sujeito é peça-chave na constituição da teoria do discurso. Distanciando-se da noção de indivíduo e de sujeito empírico, o sujeito discursivo, inserido em uma certa formação social, é levado a identificar-se com uma formação ideológica representada por uma formação discursiva e a enunciar de determinada maneira em um dado momento da história e não outro (PÊCHEUX, 1997). A voz do sujeito revela o lugar social que ocupa, isto é, expressa um conjunto de outras vozes integrantes de dada realidade social. Sendo assim, o sujeito é aquele que "carrega consigo marcas do social, do ideológico, do histórico e tem a ilusão de ser a fonte do sentido." (GRIGOLETTO, 2005, p. 1).

O conceito de discurso se distancia da noção de fala e do esquema tradicional de comunicação, podendo ser concebido como:

"objeto teórico da $\mathrm{AD}$ (objeto histórico-ideológico), que se produz socialmente através de sua materialidade específica (a língua); prática social cuja regularidade só pode ser apreendida a partir da análise dos processos de sua produção, não dos seus produtos..." (UNIVERSIDADE FEDERAL DO RIO GRANDE DO SUL).

Pode-se dizer ainda que o discurso inscreve-se na tensão entre o mesmo e o diferente, entre o já-dito e o a-se-dizer, sendo atravessado por vários outros que o precederam e que já estão postos em outros contextos sociais. Esses dizeres já-ditos e esquecidos, que sustentam e tornam possível todo o dizer, constituem a memória discursiva ou interdiscurso. Assim, para que nossas palavras tenham sentido é preciso que elas já façam sentido. (ORLANDI, 2003).

Marca-se que, enquanto alguns sentidos são censurados, silenciados, outros, pela força da repetição, tornam-se naturalizados, mas, ainda que legitimados, estão sujeitos a furos e deslocamentos, rupturas dadas pela história e pelo jogo tenso das relações ideológicas de poder entre os sujeitos. É a ideologia que regula os sentidos possíveis para o sujeito em determinadas condições. Neste contexto, a Análise do Discurso apresenta o conceito de efeitos de sentido, duvidando da existência da objetividade, da neutralidade, do sentido único, verdadeiro e transparente: 
"o sentido não existe em si, mas é determinado pelas posições ideológicas colocadas em jogo no processo sócio-histórico em que as palavras são produzidas. As palavras mudam de sentido segundo as posições daqueles que as empregam." (ORLANDI, 2003, p. 42-43).

Sendo assim, sugere-se que a visão positivista que marcou e, por muitas vezes, ainda marca a concepção de arquivo, seja substituída por uma que leve em conta o interdiscurso, as condições de produção dos discursos materializados nos documentos arquivísticos, a chamada exterioridade que é descrita abaixo:

Conforme Orlandi (2001), as condições de produção (exterioridade e processo histórico-social) são constitutivas do discurso visto que elas compreendem os sujeitos e a situação e podem ser definidas, em sentido amplo, como sendo as relações entre as classes sociais, as disputas de interesses e as tensões decorrentes da manutenção ou ruptura com o poder. Em sentido restrito, as condições de produção dizem respeito aos dados situacionais no momento em que o sujeito enuncia a partir da posição que lhe foi possível ocupar. (FERRAREZI; ROMÃO, 2006).

A partir deste momento, tentar-se-á construir relações entre os conceitos de documento, arquivo e memória e a teoria da Análise do Discurso.

\section{O DOCUMENTO ARQUIVÍSTICO}

São vários os sentidos atribuídos ao documento, ao longo do tempo, pelas áreas de Ciência da Informação, Arquivística, e História. Por meio de tais significações, simples ou complexas, o documento é configurado como sendo tanto uma informação registrada (BELLOTTO, 2002), quanto um monumento, uma construção social. Para a Análise do Discurso, os documentos materializam um ou mais discursos, carregando em suas linhas toda uma rede de memória que suscita muito mais do que uma leitura literal do texto. A maioria das concepções atribuídas ao documento não consideram tais elementos discursivos. Dentre elas, podemos citar a que o caracteriza como uma informação existente em um suporte: “Conjunto constituido por un soporte y por la información que conlleva, utilizable con fines de consulta o como prueba." (LÓPES YEPES, [2002], p.145).

... documento é um suporte com uma informação, que poderá ensinar algo a alguém. De forma simples, podemos dizer que o 'documento é uma informação, de qualquer tipo, sobre um suporte de qualquer tipo', 
ou, se colocarmos a definição ao contrário, 'documento é um suporte modificado por uma informação’ (Vazquez, S.D. e Lodolini, 1995). (BELLOTTO, 2002, p.22).

O documento, que era visto como sinônimo de texto impresso, tem seu conceito expandido, atualmente, podendo abranger uma infinidade de suportes (eletrônico, audiovisual, tridimensional, etc.), o que é observado nas definições de documento presente na literatura científica de diversas áreas e nas três definições apresentadas a seguir:

\footnotetext{
"registro de uma informação independentemente da natureza do suporte que a contém." (ASSOCIAÇAO BRASILEIRA DE NORMAS TÉCNICAS, 1986, p.3).

“"Documento de toda a expressão em linguagem natural ou convencional ou qualquer outra expressão gráfica, sonora ou imagem, fixada em qualquer tipo de suporte material, inclusive o suporte diplomático' (Lei do Patrimônio Histórico Espanhol).” (BELLOTTO, 2002, p.22).

“Há que tomar a palavra 'documento' no sentido mais amplo, documento escrito, ilustrado, transmitido pelo som, a imagem, ou de qualquer outra maneira." (LE GOFF, 1984, p.98).
}

Considerar que estas concepções não-discursivas de documento são simples e reducionistas não significa anulá-las, mas sim, propor que, além delas, e de seu aspecto físico, seja pensada a injunção ideológica de constituição do documento. Uma visão, ainda muito comum, decorrente do pensamento positivista, corresponde à concepção do documento como uma prova, uma verdade absoluta, dotado de imparcialidade. Segundo a norma técnica que define os termos a serem utilizados no arquivo, o documento arquivístico é "aquele que, produzido ou recebido por uma instituição pública ou privada, no exercício de suas atividades, constitua elemento de prova ou de informação". (ASSOCIAÇÃO BRASILEIRA DE NORMAS TÉCNICAS, 1986, p.3). Algumas das características, qualidades comumente atribuídas a este tipo de documento, supostamente, lhe confeririam o valor probatório. Tais características, que podem ser discutidas à luz da teoria discursiva, são mencionadas por Bellotto (2002, p.25): imparcialidade (em sua criação), autenticidade (nos procedimentos), naturalidade (na acumulação), organicidade (em seu relacionamento com os outros documentos do conjunto) e unicidade (no conjunto). 
Criticam-se, a partir da teoria da $\mathrm{AD}$, os princípios de imparcialidade e autenticidade atribuídos aos documentos, visto que sua produção é sempre regulada e constituída por mecanismos ideológicos. Tal visão é compartilhada por pesquisadores de outras áreas, como Le Goff (1984, p.103), para quem

"o documento não é inócuo [...] o testemunho, o ensinamento (para evocar a etimologia) que ele traz devem ser em primeiro lugar analisados desmistificando-lhe o seu significado aparente [...] no limite, não existe um documento-verdade."

Marca-se que a acumulação de documentos não é um processo natural, posto que há uma seleção do que é considerado relevante permanecer no arquivo, ou não. Já os princípios de organicidade e unicidade não significam o documento como prova, mas sim, como integrante de uma rede de memória que o significa e estabelece um vínculo entre os documentos, constituído no contexto de sua produção. O conceito de memória perpassa os documentos, tanto pela $\mathrm{AD}$ que aponta a memória constitutiva do dizer (PÊCHEUX, 1997) quanto pela História que os considera materiais de memória (social). Tais concepções podem ser vistas como complementares. Segundo Le Goff (1984, p.95), os “materiais da memória podem apresentar-se sob duas formas principais: os monumentos, herança do passado, e os documentos, escolha do historiador."

O documento considerado como monumento constitui uma acepção mais ampla do termo e uma possível relação com a $\mathrm{AD}$. Cabe dizer que o monumento é pensando como um sinal do passado, segundo o historiador Le Goff (1984, p.95): “é tudo aquilo que pode evocar o passado, perpetuar a recordação, por exemplo, os actos escritos." Os monumentos são construídos com a intenção de lembrar algo, havendo uma escolha do que deve ser lembrado. Segundo a perspectiva da Análise do Discurso, podemos pensar que os documentos, além de serem uma escolha ideológica - em que alguns sentidos são naturalizados como dominantes, devendo ser lembrados e institucionalizados, e outros são censurados, devendo ser esquecidos e apagados - são também, como os monumentos, portadores de uma herança: a memória discursiva de que eles são constituídos e que os sustenta, permitindo a sua significação. Através da AD, pode-se, também, desmistificar a noção de uma intencionalidade guiada pelo sujeito, pois:

A partir da visão de discurso na perspectiva da $\mathrm{AD}$, redefine-se o conceito de sujeito, que deixa de ser aquele que tem o controle 
intencional e consciente de seu dizer. Ele passa a ser visto como descentrado, descontínuo, determinado ideologicamente por formações discursivas que o precedem, dentro das quais se constituem as diferentes posições de sujeito, assim como os sentidos e seus efeitos. (FRÊITAS, 2002).

Assim sendo, os documentos de arquivo podem ser vistos como resultado de construções e de relações sócio-ideológicas, e não uma verdade absoluta, como se pensava no século XIX e início do XX. Neste âmbito, pode-se pensá-los não apenas como um recorte da realidade, mas como escolhas que direcionariam a construção de um arquivo formado por certos documentos e não outros. Isso nos remete a pensar que tais "escolhas" foram produzidas sob determinadas condições de produção, e que existe a possibilidade de haver o forjamento de documentos que, apenas por estarem acondicionados em um arquivo, poderiam ser vistos como prova, reflexo da instituição, autênticos, o que nos é narrado na ficção escrita por Flanagan (2003):

"o velho dinamarquês fora escolhido pelo comandante para alterar todos os documentos da colônia, de tal modo que eles refletissem não a realidade, e sim as expectativas." (Ibid., p.279).

"Pois o mundo já não existia para se transformar num livro. Agora um livro existia cuja ambição obscena era se transformar no mundo." (Ibid., p. 286).

Sendo assim, surge a seguinte questão: em que medida o documento (arquivístico) atende aos objetivos da entidade produtora/acumuladora? Passam-se agora para as questões relativas ao arquivo.

\section{O ARQUIVO}

Muitas das questões levantadas até aqui em relação aos documentos podem ser aplicadas aos arquivos. Assim como os princípios atribuídos aos documentos, os que se referem ao arquivo também podem ser discutidos, são eles: princípio da proveniência, da organicidade, da unicidade, da indivisibilidade e da cumulatividade. (BELLOTTO, 2002). A análise destes princípios aponta convergências e divergências em relação à teoria do discurso, quais sejam, em consonância com a $\mathrm{AD}$, podemos inferir que $\mathrm{o}$ significado do documento (que, no caso, determinará a escolha do lugar a ser ocupado 
no arquivo, tem relação com o conceito de condições de produção, isto é, com a exterioridade que o constitui. Isso nos permite inferir que mudando o lugar do documento no arquivo ou alterando a ordem das escolhas do que será posto em arquivo, mudam-se também os sentidos postos em discurso e instala-se uma outra inscrição histórica de valor e significado dos documentos. A AD também apregoa tal postulado sustentando, por exemplo, que a mudança de uma palavra por seu sinônimo dentro de um texto ou a alteração de uma ordem da frase também produzem outros efeitos de sentido, já que as palavras não são entendidas como se estivessem em estado de dicionário.

$\mathrm{Na}$ contramão do que postulam estes princípios atribuídos ao arquivo, sugere-se que o documento arquivístico não seja concebido como aquele que deve ocupar um único lugar, que constrói relações rígidas, sedimentadas, mas sim, como aquele que ocupa um lugar estabelecido sócio-histórico-ideologicamente. Assim sendo, ao mudarem a exterioridade que afeta a constituição de arquivo, de memória e de instituição produtora/acumuladora dos documentos, mudam-se também a organização e a forma de se pensar e significar o arquivo. Como já foi dito, o arquivo não é formado por uma acumulação natural de documentos; o princípio de cumulatividade desconsidera o processo de escolha e legitimação de alguns sentidos em detrimento de outros, que é descrito por Smit como processo de institucionalização da informação:

Pode-se portanto estabelecer que a informação estocada em arquivos e bibliotecas é registrada e, após avaliação, considerada útil: o fruto deste processo é a institucionalização da informação uma vez que decorrente de decisões institucionais (ou, por extensão, sociais). Independentemente de suportes ou códigos, a informação é institucionalizada por arquivos e bibliotecas: este é certamente um produto da área que confere 'status' a certas informações e nega a outras [...] a institucionalização da informação encontra sua justificativa cultural, social e econômica à medida que esta informação é disponibilizada para a sociedade, ou comunidade, que financia a manutenção do estoque. (SMIT, 2003, p.8).

Delineou-se, ao longo do tempo, uma forma simplista de se pensar o arquivo, assim como ocorreu com o documento. Tal forma pode ser percebida em grande parte das definições de arquivo que privilegiam seu aspecto físico, material, técnico. Neste contexto, o termo arquivo pode se referir ao conjunto de documentos, ao móvel que os condiciona e ao arquivo como instituição: 
Designação genérica de um conjunto de documentos produzidos e recebidos por uma pessoa física ou jurídica, pública ou privada, caracterizado pela natureza orgânica de sua acumulação e conservado por essas pessoas ou por seus sucessores, para fins de prova ou informação. De acordo com a natureza do suporte, o arquivo terá a qualificação respectiva, como, por exemplo, arquivo audiovisual, fotográfico, iconográfico, de microformas, informático; O prédio ou uma de suas partes, onde são guardados os conjuntos arquivísticos; Unidade administrativa cuja função é a de reunir, ordenar, guardar e dispor para o uso conjuntos de documentos, segundo os princípios e técnicas arquivísticas; Móvel destinado à guarda de documentos. (ASSOCIAÇAO BRASILEIRA DE NORMAS TÉCNICAS, 1986, p.1-2).

Arquivos são conjuntos orgânicos de documentos produzidos/recebidos/acumulados por um órgão público, uma organização privada ou uma pessoal, no curso de suas atividades, independentemente do seu suporte, e que, passada sua utilização ligada às razões pelas quais foram criados, pode, ser preservados, por seu valor informativo, para fins de pesquisa científica ou testemunho sociocultural. $\mathrm{Na}$ palavra de um dos mais importantes arquivistas italianos, Elio Londolini, 'arquivo é a sedimentação documentária das atividades administrativas, cujos documentos estão ligados por um vínculo original, necessário e determinado' (Londolini, 1991). (BELLOTTO, 2002, p.18).

Dialogando com estes sentidos sobre o arquivo, estão aqueles que o significam, de forma estática, como um lugar de armazenamento, depósito, sedimentação de informações, coleção homogênea de dados:

\footnotetext{
“"Arquivo é a acumulação ordenada de documentos criados por uma instituição ou pessoa no curso de sua atividade e preservados para a realização dos fins políticos, legais e culturais daquela instituição ou pessoa'(Casanova, 1928)." (BELLOTTO, 2002, p.19),

[é] conjunto de registros relacionados, tratados como um todo. Principal depósito de informações, organizadas de tal maneira que possibilite sua recuperação por meios predeterminados; grupos de dados gravados ou em qualquer outro suporte de armazenamento; local ou móvel onde se guardam, ordenadamente, documentos em geral; coleção homogênea de dados, passível de ser memorizada e processada por um computador; conjunto de documentos que, independentemente da natureza ou suporte, são reunidos por processo de acumulação ao longo das atividades de pessoas físicas ou jurídicas, públicas ou privadas e conservados em decorrência de seu valor; conjunto de documentos, com datas de publicação, forma e suporte material diversos, elaborados e recebidos por uma pessoa ou um organismo público ou privado, em função de sua atividade, organizados e conservados de forma permanente. (SANTOS; RIBEIRO, 2003, p.21).
} 
Tais características atribuídas ao arquivo têm a pretensão de constituírem uma prova de que a coleção arquivística, sendo resultado de um "natural processo de acumulação", seria provida de credibilidade e autenticidade, valores presentes na definição de arquivo encontrada em López Yepes ([2002], p.140): "Un archivo es un conjunto de documentos en el que la información tiene una garantía de credibilidad, de autenticidad y de rigor em el proceso de creación de estatos documentos." Como já foi dito, a teoria discursiva não acredita nesse modo de designar o arquivo, pois considera que, ao ser enunciado um conjunto de documentos em um arquivo, silenciam-se outros, que poderiam significá-lo de outro modo. Atribui-se uma concepção mais ampla ao arquivo ao considerá-lo como um lugar de memória (SILVA, 1999), organização que visa instituir, arranjar e preservar uma memória histórica, representando o modo como a ordem do saber é estruturada. Assim, há o estabelecimento de uma ordem não apenas dos documentos, mas do conhecimento, do saber que pode e deve ser propagado, preservado e acessado por determinados sujeitos: a ordem do discurso da qual nos fala Foucault (2005, p.37):

Creio que existe um terceiro grupo de procedimentos que permitem o controle dos discursos. Desta vez, não se trata de dominar os poderes que eles têm, nem de conjurar os acasos de sua aparição; trata-se de determinar as condições de seu funcionamento, de impor aos indivíduos que os pronunciam certo número de regras e assim de não permitir que todo mundo tenha acesso a eles. Rarefação, desta vez, dos sujeitos que falam; ninguém entrará na ordem do discurso se não satisfazer a certas exigências ou se não for, de início, qualificado para fazê-lo. Mais precisamente: nem todas as regiões do discurso são igualmente abertas e penetráveis; algumas são altamente proibidas (diferenciadas e diferenciantes), enquanto outras parecem quase abertas a todos os ventos e postas, sem restrição prévia, à disposição de cada sujeito que fala.

Tal ordem constitui-se como um instrumento de poder que institui um documento em detrimento de outros, um arquivo ao invés de outro, construindo uma memória social resultante de uma disputa de interpretações:

a memória social não é natural, mas construída. Neste sentido, B. Mariani (1998) observa que uma memória social que se narra resulta de um processo histórico de disputa de interpretações para os acontecimentos presentes ou já ocorridos, sendo que, como resultado do processo, ocorre a predominância de uma de tais interpretações e um (às vezes aparente) esquecimento das demais. Naturaliza-se, assim, um sentido 
"comum" à sociedade, ou, em outras palavras, mantém-se imaginariamente o fio de uma lógica narrativa. (Mariani, 1998, p. 34). (PAYER, 2005, p.51-2).

Percebe-se nestas afirmações, a relação entre a memória social e memória discursiva (interdiscurso), no contexto arquivístico. Pode-se dizer que os documentos arquivísticos, constituindo a memória institucionalizada, são instrumentos de condensação de sentidos para que haja perpetuação da memória social que, por sua vez, é construída através de discurso(s), em que pese a contínua retomada do interdiscurso, da memória discursiva. E é essa memória discursiva que se liga à concepção de arquivo para a Análise do discurso, o que é confirmado por Pacífico e Romão (2006, p.78):

Essa concepção da memória do dizer nos conduz ao conceito de arquivo, cunhado por Pêcheux (1997, p. 56) e "[...] entendido em sentido amplo como campo de documentos pertinentes e disponíveis sobre uma questão". Tal campo não diria respeito a um grupo de documentos físicos a serem guardados em gavetas ou prateleiras, mas a zonas da memória a que o sujeito do discurso teve acesso, a espaços de dizer a que ele já se submeteu anteriormente e, por fim, a regiões do já-la às quais se filiou em outros momentos e nas quais buscou "a voz sem nome" para significar-se.

Dizer que o conceito de arquivo na $\mathrm{AD}$ é diferente do(s) existente(s) na Arquivística, Ciência da Informação e História, não significa que ele não possa dialogar com estas áreas. Frequentemente analisado pelo ponto de vista técnico, o arquivo pode ser pensado também pelo aspecto discursivo-ideológico proposto pela $\mathrm{AD}$, considerando os materiais de arquivo como "gestos simbólicos que se inscrevem na história." (NUNES, 2005), ampliando-se, assim, o escopo teórico de discussões em torno do tema. Pelo viés da $\mathrm{AD}$, o arquivo é considerado pela multiplicidade de dizeres e de sentidos, que só podem constituí-lo quando concebido como arquivo discursivo, podendo ser lido sob uma outra ótica, que considere a historicidade e desmistifique o mito do sentido único:

Trabalhar a historicidade implica em observar os processos de constituição dos sentidos e com isso desconstruir as ilusões de clareza e de certitude. Ao mesmo tempo, trabalhar a historicidade na leitura de arquivos leva a realizar percursos inusitados, seguindo-se as pistas lingüísticas, traçando percursos que desfazem cronologias estabelecidas, que explicitam a repetição de mecanismos ideológicos em diferentes momentos históricos, que localizam deslocamentos e rupturas. Desse modo, o arquivo não é visto como um conjunto de "dados" objetivos dos quais estaria excluída a espessura histórica, mas 
como uma materialidade discursiva que traz as marcas da constituição dos sentidos. O material de arquivo está sujeito à interpretação e, mais do que isso, à confrontação entre diferentes formas de interpretação e, portanto, não corresponde a um espaço de "comprovação", onde se suporia uma interpretação unívoca." (NUNES, 2005).

Assim como não há um sentido pré-concebido, em um arquivo não há um padrão rígido de organização dos documentos a ser seguido, uma ordem impecável a ser mantida. Da mesma forma, o trabalho em um arquivo não deve ser mecânico, voltado para o interior do mesmo, mas sim, investigativo, reflexivo, buscando-se as pistas deixadas pelos sujeitos, pelos dizeres enunciados e, também, pelos silenciados, constituindo, assim, uma escavação arqueológica nos moldes propostos por Michel Foucault. Nesta perspectiva, o arquivo se constituiria como um verdadeiro organismo vivo e mutável.

\section{UM ESTUDO DE CASO}

A discussão sobre documento, arquivo e memória discursiva será mobilizada para interpretar a página eletrônica do Movimento dos Trabalhadores Rurais Sem Terra. Sabemos que a textualidade eletrônica apresenta uma topologia em links (LÉVY, 1999, 2001), que podem se colar e/ou romper mutuamente, construindo e rompendo os fios de uma teia de inúmeros nós (ROMÃO, 2004); rede esta em que cada nó é uma rede em si. Considerando a rede eletrônica a partir da lente da teoria do discurso e levando em conta as noções de arquivo (PÊCHEUX, 1982), heterogeneidade e memória, inferimos que as palavras colocadas em discurso nos links só fazem e constroem sentidos para o sujeito que tiver acesso ao interdiscurso e aos sentidos já dados pela superfície da memória. Por exemplo, o link de um movimento social de luta pela terra só é interpretado por um sujeito que já tiver acesso aos sentidos socialmente construídos sobre o que é um movimento social, sobre o que isso significa a respeito da desigualdade de poderes em um país com a estrutura agrária concentrada como a brasileira, sobre quais vozes se organizam nesse tipo de movimento e sobre como o processo de reivindicação já foi silenciado em outros contextos históricos e hoje pode ser discursivizado. Nesse sentido, concordamos com Courtine (1999, p. 22) quando ele afirma que "memória e esquecimento são, assim, indissociáveis na enunciação do político". E, no nosso caso, é preciso levar em conta o político, visto que estar na rede 
inscreve um novo modo de materializar efeitos de resistência, reivindicação e denúncia, fazendo falar a voz de um sujeito que muitas vezes foi silenciado e não pôde dizer palavras de luta. Isso nos leva a retornar ao conceito de arquivo já falado anteriormente, pois implica considerar a multiplicidade de dizeres e de sentidos, a historicidade e a memória sustentadora dos atos de linguagem.

Dessa forma, estar na rede eletrônica significar apresentar um arquivo organizado por sujeitos que estabeleceram uma determinada ordem para colocar em discurso os sentidos sobre a realidade agrária; também significa ocupar um lugar na teia pública e aberta à visitação de vários, instalando um endereço fixo para dizer de si e delimitando um lugar imaginário, no qual relatos, estratégias, notas de repúdio, protestos, abaixoassinados etc podem ser materializados e estruturados não por um princípio de acumulação natural, mas por um processo legitimação de alguns sentidos em detrimento de outros, o que nos convida a considerar, uma vez mais, a historicidade, a ideologia e o político.

Assim, a página eletrônica do MST é entendida aqui como um arquivo discursivo que marca a inscrição histórica dos sentidos de luta pela terra e apresenta um outro modo de constituição, produção e circulação dos dizeres, qual seja, aquele em que vários enunciados são selecionados e emprestados de várias outras páginas, enovelando a voz de vários sujeitos, colocando lado a lado águas de diferentes rios e também o murmúrio de vários deles.

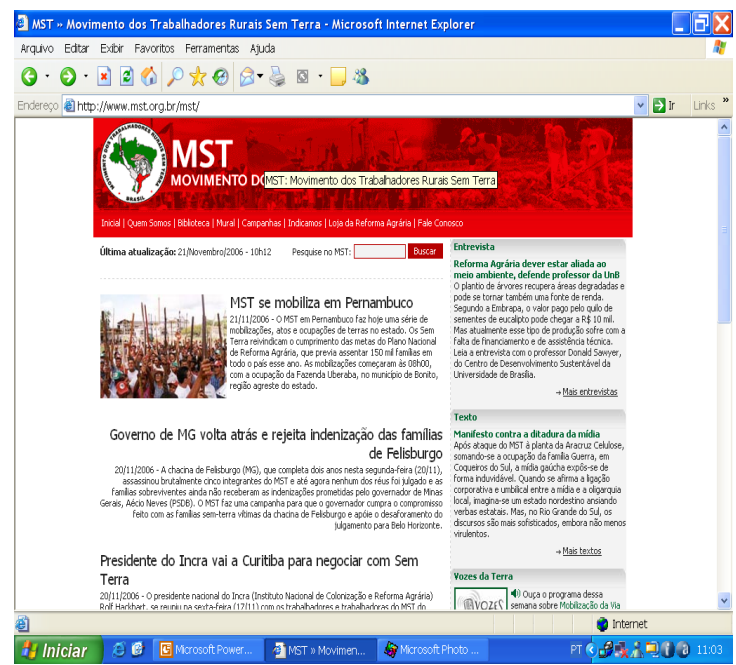

Página eletrônica do MST 
Também ressaltamos que, em relação à questão agrária, o www propicia a emergência de arquivos, cujos sentidos questionam aqueles materializados pela formação discursiva tida como oficial, dominante e legitimada, promovendo, assim, a instabilidade e a possibilidade de confronto, de espaços de tensão, disputas e conflitos. Temos, então, links e sites onde vazam os ditos já estabelecidos e cristalizados como únicos possíveis de serem ditos como é o caso do site em estudo, em cuja trama várias vozes são postas em discurso, em cuja teia pretendemos flagrar a heterogeneidade e os efeitos de memória. $\mathrm{O}$ arquivo discursivo que ora interpretamos é, assim, ordenado e estabelecido a partir de um lugar sócio-histórico que permite organizar os relatos, notícias, fotografias, biblioteca etc de um modo e não de outro.

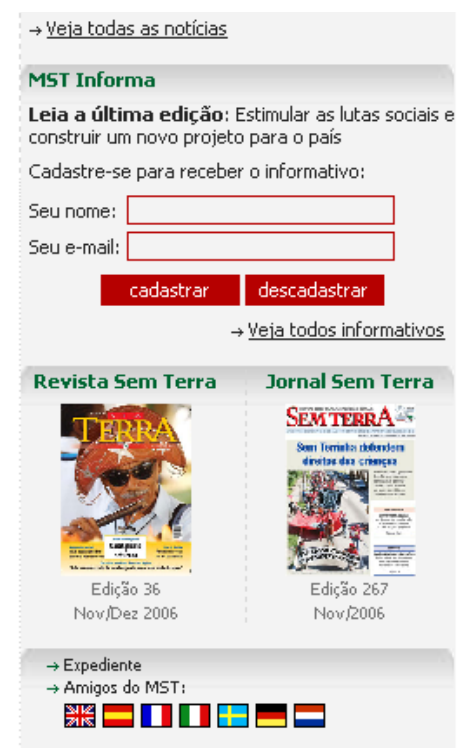

Página eletrônica do MST

A voz do próprio movimento social, marcada lingüisticamente pela formulação "MST informa", cria o efeito de ser esta página uma segura fonte de informação, ou seja, estamos no fio discursivo (intradiscurso) em que o MST fala como movimento organizado, como organização popular, indiciando enunciados sobre a realidade, não apenas agrária, mas, sobretudo, social do país. Destacamos que há "amigos do MST" que garantem a tradução desta página para outros idiomas, globalizando os efeitos reivindicatórios de algo que poderia ficar apenas em idioma português, o que restringiria a circulação dos dizeres sem-terra no ciberespaço. "Revista Sem Terra" e “Jornal Sem Terra" fazem falar um modo de o movimento social estar na mídia, 
criando, além de uma rede própria de informação, também um modo de inscrição e identidade da posição-sujeito sem-terra. Observamos como o site, a revista, o jornal e as bandeiras de vários países constroem uma malha dialógica, consolidando os efeitos do que se imagina ser a mesma formação discursiva e marcando um modo de esse arquivo dialogar com outros arquivos postos em discurso em outros lugares, isso nos dá pistas de que a linguagem é também esse movimento permanente de retomadas, empréstimos, deslocamentos e diálogos com palavras já ditas em outro lugar. O arquivo discursivo, dessa maneira, possibilita um alargarmento conceitual para o sujeito que lida com a informação, posto que toma não apenas um universo de dados organizados em si mesmo, mas tende a considerar os vários de campos de documentos dados sobre uma questão, os que estão ditos e os que foram silenciados, os manifestos e os apagados.

Continuando a nossa análise, a página eletrônica do MST apresenta também uma biblioteca eletrônica com vários links nos quais observamos a presença de várias vozes de sujeitos que apóiam o MST e/ou a reforma agrária ou então se filiam ao interdiscurso que sustenta a necessidade de mudanças sociais para o crescimento do país. Algumas entradas desse grande arquivo "Biblioteca" serão interpretadas; buscamos compreender o modo como são produzidos sentidos na forma de nomear esses links e no modo como eles engendram heterogeneidade e memória. O primeiro deles chama-se "BibliotecaDados" e é seguido por links cuja designação são "Acampamentos", “Assentamentos do MST em 2004", “Prisões 2004”. Percebemos aqui a marca de uma outra voz que indicia os efeitos de suposta exatidão, objetividade e autoridade dos órgãos de consulta e de pesquisas. A apresentação de estatísticas teria o poder de conferir credibilidade ao dizer da página eletrônica, emprestando um efeito de realidade à violência que os semterra sofrem, às mobilizações que organizam e às conquistas de terra consolidadas em assentamentos. 


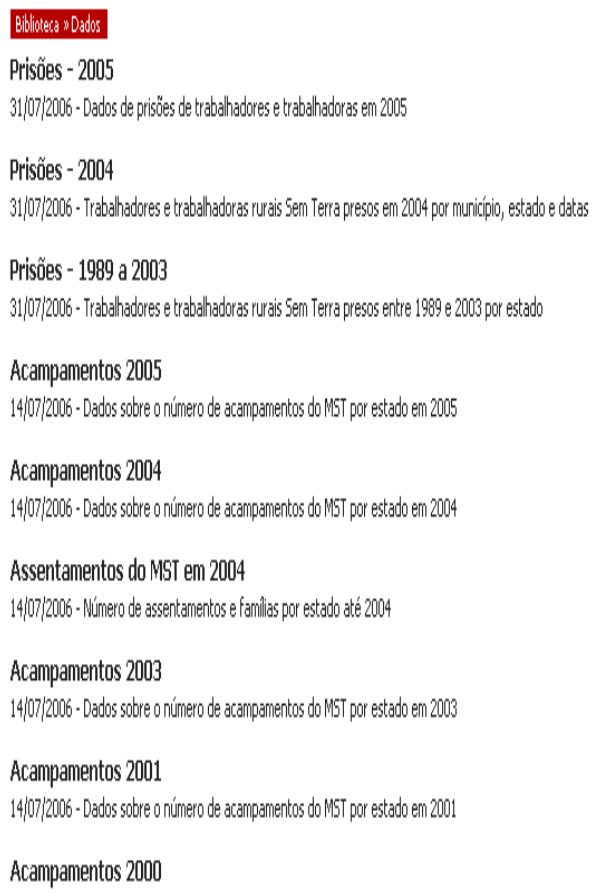

Página eletrônica do MST

Esse efeito de realidade é sustentado pelo ideário considerado científico das pesquisas quantitativas e pela forma como os números são falados como prova irrefutável e contundente, ou seja, o sujeito, afetado pelo efeito ideológico de evidência de que para comprovar é preciso quantificar, abre uma janela na página eletrônica, marcando no canto inferior esquerdo que ela é desenvolvida por "ibBrasil".

\begin{tabular}{|l|r|}
\hline & \\
\hline Estados & Número de Famílias \\
\hline \hline Alagoas & \\
\hline Bahia & 4.543 \\
\hline \hline Ceará & 30.862 \\
\hline DF e Entorno & 1.300 \\
\hline \hline Espírito Santo & 2.148 \\
\hline
\end{tabular}

Reproduzimos acima apenas uma pequena parte da tabela nomeada como “Acampamentos 2005"; julgamos importante anotar que a voz manifesta nesse link 
indicia uma outra voz, que juntamente com a do sem-terra, trança sentidos de denúncia da morosidade com que a reforma agrária tem sido feita no país. Temos, então, um arquivo dentro de um outro grande arquivo, a voz de um órgão de pesquisa ou de tratamento de dados estatísticos dentro da voz do movimento social, indicando a filiação à mesma formação discursiva e materializando o sentido de que muitas famílias esperam seu lote de terra, ou melhor, de que são muitos os excluídos dessa terra. Observamos aqui, dentro de um arquivo instituído, o empréstimo de dados de um outro arquivo, criando, novamente, o efeito dialógico entre campos de documentos sobre a questão agrária, enfim, entre discursos. Ainda na "Biblioteca", temos os outros links nos quais é manifesto o mesmo entrelaçamento de vozes: há o link "BibliotecaCartazes", em que estão postos os cartazes do movimento, de festas populares, de campanhas por justiça, de denúncia da impunidade; há o link com "BibliotecaCharges", onde estão enumerados vários nomes de chargistas conhecidos que emprestam seu traço para, também eles, colocarem-se como sujeitos de um discurso de denúncia (vale destacar aqui que, clicando no nome do artista, o internauta acessa um conjunto de charges sobre a questão agrária); há, ainda "Biblioteca-Livros", "Biblioteca-Textos", "Biblioteca-Vídeos" e "Biblioteca-Lutadores e lutadoras do povo", em que as marcas de heterogeneidade mostrada (AUTHIER-REVUZ, 1990) estão pontuadas.

Julgamos interessante marcar como no link "Biblioteca-Fotos", há enunciados que colocam em discurso o efeito de indignação e revolta e, depois de acessá-los, estão dispostas fotografias do movimento social em datas comemorativas, dias de mobilização ou jornadas de luta. 


\section{Fotografia: Pilippo Podestà}

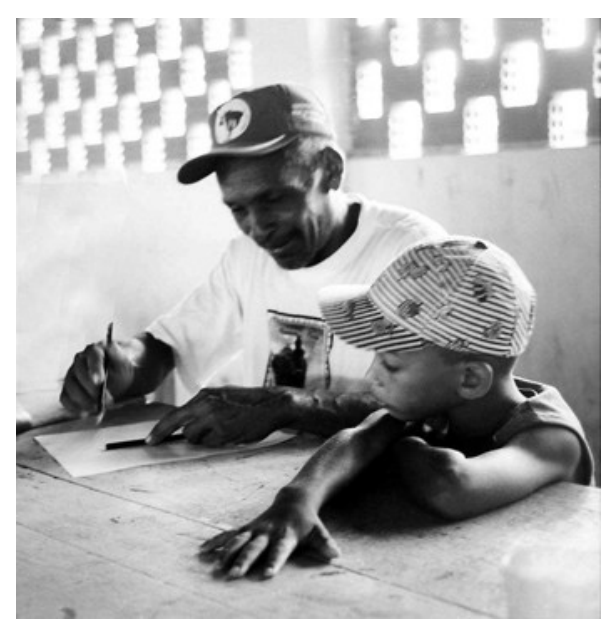

Página eletrônica do MST

Nas fotografias, temos também a marca do sujeito-fotógrafo que, com os recursos de enquadramento, cor, tamanho, planos etc, faz falar um modo de inscrever sentidos e construir recortes sobre a realidade, neste caso, sobre a ocupação na Avenida Paulista ou a educação nos acampamentos. O nome dos fotógrafos materializa esse olhar outro, que pode ou não ser um sujeito sem-terra, mas certamente dialoga com ele no modo de discursivizar a questão agrária e social do país.

\section{CONSIDERAÇÕES FINAIS}

Como vimos anteriormente, a página do MST marca um lugar discursivo de resistência dos sentidos sobre a luta pela terra no país, inscrevendo e atualizando as redes da memória já ditas em outros contextos sociais e, para tal, entrelaça diversas vozes, colocando em movimento diversos arquivos. Sobre arquivos gostaríamos de pontuar ter considerações finais: a primeira é a de que eles são vistos aqui não como um recorte da realidade, mas como resultado de injunções ideológicas que direcionariam a construção de uma ordem formada por certos documentos e não outros, o que implica considerar que essa ordem foi produzida sócio-historicamente. Essa assertiva combina a nossa segunda consideração, tão cara à teoria do discurso: a que de, ao dizer, o sujeito sempre cala algo, assim, um arquivo ordenado de uma maneira, crivado por uma seqüência de documentos, mobilizador de certas fontes, fixador de um modo de dizer sobre um tema, sempre silencia outra ordenação, outra organização, outros modos possíveis de dizer e 
outras fontes. Nesse sentido, a reflexão sobre documento, arquivo e memória discursiva nos convida a refletir sobre a terceira consideração desse trabalho: a necessidade de interpretar os processos de produção, constituição e circulação dos sentidos levando em conta o político, compreendendo a voz dos sujeitos e seus sentidos sempre em movimento, em discurso.

\section{REFERÊNCIAS BIBLIOGRÁFICAS}

ASSOCIAÇÃO BRASILEIRA DE NORMAS TÉCNICAS. NBR 9578: Arquivos. Rio de Janeiro: [s.n], 1986.

AUTHIER-REVUZ, Jacqueline. Heterogeneidade(s) enunciativa(s). Cadernos de Estudos Lingüísticos, Campinas, n.19, 1990.

BELLOTTO, Heloísa Liberalli. Arquivística: objetos, princípios e rumos. São Paulo: Associação de Arquivistas de São Paulo, 2002.

COURTINE, Jean Jacques. O chapéu de Clémentis. In: INDURSKY, Freda; FERREIRA, Maria Cristina Leandro (Orgs.). Os múltiplos territórios da Análise do Discurso. Porto Alegre: Editora Sagra Luzzatto, 1999.

FERRAREZI, Ludmila; ROMÃO, Lucília Maria Sousa. O discurso jornalístico sobre a morte de Dorothy Stang: a textualização nas páginas da revista Veja. Achegas.net, Rio de Janeiro, n.30, jul/ago 2006. Disponível em: $<$ http://www.achegas.net/numero30/lucilia_ludmila_30.pdf $>$.

FLANAGAN, Richard. O livro dos peixes de Willian Gould: romance em doze peixes. São Paulo: Companhia das Letras, 2003.

FOUCAULT, Michel. A ordem do discurso. 12. ed. São Paulo: Edições Loyola, 2005.

FRÊITAS, Ariadne Castilho de. O canto polifônico da sedução no discurso político. Revista Ciências Humanas, Taubaté, v. 8, n. 2, 2002. Disponível em: $<\quad$ http://www.unitau.br/prppg/publica/humanas/download/ocantopolifonico-N22002.pdf $>$.

GRIGOLETO, Evandra. Do lugar social ao lugar discursivo: o imbricamento de diferentes posições-sujeito. In: SEMINÁRIO DE ESTUDOS EM ANÁLISE DO DISCURSO, 2.,2005, Porto Alegre. Anais eletrônicos. Porto Alegre: UFRGS, 2005. Disponível em: <http://www.discurso.ufrgs.br/sead/doc/sujeito/evandra.pdf $>$. Acesso em: 22. fev. 2006.

LE GOFF, Jacques. Documento/Monumento. In: Einaudi. Porto: Imprensa nacional - Casa da Moeda, 1984. p. $95-106$ 
LÉVY, Pierre. Cibercultura. São Paulo: Editora 34, 1999.

. O Virtual. São Paulo, SP: Editora 34, 2001.

LÓPEZ YEPES, José (Coord.). Manual de Ciencias de la Documentación. 2.ed. Madrid: Pirámide, [2002].

NUNES, José Horta. Leitura de arquivo: historicidade e compreensão. In: SEMINÁRIO DE ESTUDOS EM ANÁLISE DO DISCURSO, 2, 2005, Porto Alegre. Anais eletrônicos... Porto Alegre: UFRGS, 2005. Disponível em: $<$ http://www.discurso.ufrgs.br/sead2/doc/interpretacao/Jose_horta.pdf $>$.

ORLANDI, Eni P. Análise de discurso: princípios e procedimentos. 5.ed. Campinas: Pontes, 2003.

PACÍFICO, Soraya Maria Romano; ROMÃO, Lucília Maria Sousa. A memória e o arquivo produzindo sentidos sobre o feminino. Em questão, Porto Alegre, v.12, n.1, p.73-90, jan./jun. 2006. Disponível em: $<$ http://www.seer.ufrgs.br/index.php/EmQuestao/article/viewFile/24/9>.

PAYER, Maria Onice. Discurso, memória e oralidade. Horizontes, v. 23, n. 1, p. 47-56, jan./jun. 2005.

PÊCHEUX, Michel. Ler o arquivo hoje. In: ORLANDI, Eni P. (Org). Gestos de leitura. Campinas: Editora da Unicamp, 1982.

Semântica e Discurso: uma crítica à afirmação do óbvio. Tradução de Eni Pulcinelli Orlandi et al. 3.ed. Campinas, SP: Editora da UNICAMP, 1997.

ROMÃO, Lucília Maria Sousa. Na teia eletrônica, fragmentos da memória. In: MORELLO, Rosângela (Org.). Giros na Cidade: materialidade do espaço. Campinas: Editora da Unicamp, Labeurb, 2004.

SANTOS, Gildenir Carolino; RIBEIRO, Célia Maria. Acrônimos, siglas e termos técnicos: Arquivística, Biblioteconomia, Documentação, Informática. Campinas: Editora Átomo, 2003.

SILVA, Zélia Lopes da (Org.). Arquivos, patrimônio e memória: trajetórias e perspectivas. São Paulo: Editora UNESP; FAPESP, 1999.

SMIT, Johanna W. Arquivologia/Biblioteconomia: interfaces das Ciências da Informação. Informação \& Informação, Londrina, v. 8, n. 2, 2003. Disponível em: $<$ http://www.uel.br/revistas/informacao/include/getdoc.php?id=380\&article=136\&mode $=$ pdf. $>$.

UNIVERSIDADE FEDERAL DO RIO GRANDE DO SUL. Instituto de Letras. Glossário de termos de discurso. Disponível em: <http://www.discurso.ufrgs.br/> . Acesso em: 20. fev. 2006. 


\section{ABSTRACT}

That article attempts, to the light of the theory of the speech, to visit the file notion, looking for to understand as the senses on him constitutes a scientific place consolidated already and as it is possible a dialogue with the speech conception. For such, we interpreted a corpus picked in the electronic page of the Movement of the Landless Workers.

KEYWORDS: Archive, Archivistic document. Discursive memory. Movement of the Landless Workers. Discurse Analysis.

Originais recebidos em: 25/06/2007

Texto aprovado em: 14/09/2007 